\title{
Firm Heterogeneity and the Localization of Economic Activities *
}

\author{
Pamela Bombarda ${ }^{\dagger}$ \\ THEMA - Université de Cergy-Pontoise
}

July 19, 2013

\begin{abstract}
This paper examines how market access strategies, export and FDI, respond to changes in level of integration. Empirical evidence shows that both firm exports and multinational activity are affected by trade liberalization episode. To account for the strong positive correlation between export and FDI, we develop a general equilibrium model that features firm heterogeneity, trade and FDI with final and intermediate products. Different geographical spaces are considered to quantify the effect of a preferential trade agreement (PTA) on supply mode decisions, for both partner and excluded countries. The model sheds new light on the mechanisms through which geography reshapes the concentration of economic activities inside and outside the PTA area.
\end{abstract}

JEL classification: F12; F15; F23; R12

Keywords: Heterogeneous firms; PTA; Spatial networks; Intra-firm trade

${ }^{*}$ Acknowledgments: I am grateful to R. Baldwin, G. Calzolari, and G.I.P. Ottaviano for advice and encouragement. Remarks from participants at the 2007 Zeuthen Workshop in Copenhagen, at the 2007 IAW Workshop in Tuebingen, at the 2008 VIIIth RIEF Doctoral Meeting (Barcelona), at the 2012 ITSG Conference in Catania, and seminar participants at the Graduate Institute and at the Geneva University also contributed to improve this paper. All remaining errors are mine. This paper is a substantially revised version of HEI Working Paper 24/2007 entitled "The Spatial Pattern of FDI: Some Testable Hypotheses".

${ }^{\dagger}$ Corresponding author: 33 Boulevard du Port, F-95011 Cergy-Pontoise Cedex, France Tel.: +33 1342567 59; fax: +331342562 33; E-mail address: pamela.bombarda@u-cergy.fr. 


\section{Introduction}

The effect of discriminatory trade policy on reorganization of production is an important issue in international trade. However, the question concerning how a trade policy event affects export and foreign direct investment (FDI) seems under-researched. The aim of this paper is to further enrich the analysis of symmetric as well as asymmetric trade liberalization on firm's organization of production. Combining intra-firm linkages with different geographical spaces, we investigate the impacts of deeper economic integration. The firm heterogeneity structure of the model is used to evaluate the impact of asymmetric trade integration on firms' location and organization of production. Our findings show that geographical differences reduce the effect of discriminatory trade liberalization on the reorganization of modes supply strategy.

Preferential trade agreements (PTAs) allow countries to mutually grant preferential access on goods and services. PTA participation has accelerated over time and become more widespread; as of 2011 there are around 300 active agreements (WTO, 2011). PTAs serve different purposes, such as get access to larger markets or reach cheaper intermediate goods. In parallel to the increasing prominence of PTAs, there is also a growing concern about the fact that PTAs might hurt countries excluded from the agreements and thus hindering multilateral trade liberalization (see, for instance, Limao, 2007; Freund and Ornelas, 2010). PTA can in fact divert trade by substituting intra-bloc trade for trade from outside the group.

In this paper, we consider the effects of different geographical spaces (e.g. transport costs) and border trade frictions (e.g., tariffs) on the location of firms and the welfare of nations. The impact of international trade costs and transport costs on the location choices of firms have been widely studied (Behrens et al. (2007), Behrens et al. (2009) among others). Relying on the standard assumption that the two cost components affect firm location and trade patterns in the same way, this paper enriches the exiting literature by adding heterogeneous firms to investigate how deeper international integration affects firms' supply mode decisions.

Export and FDI strategies will be defined as complement when they similarly react to a trade policy event, i.e. both trade and FDI flows increase after a reduction in trade costs. On the contrary, substitution is used to indicate when these activities move in opposite directions, confirming the so called proximity versus concentration hypothesis. ${ }^{1}$ The complementarity relationship between trade and FDI relies on intra-firm trade flows which are affected by tariffs and transport costs. The way in which changes in tariffs affect the equilibrium location of export and FDI activities is crucially related to the geographical space considered. Starting with the symmetric liberalization episode, where geography plays no role, we then move to asymmetric liberalization (PTA) and focus on two geographical spaces. First, we consider different accessibility to foreign markets in terms of transport barriers. Then, we analyse the case without cross-country differences in centrality (all countries lie at the same geographical distance).

In terms of findings, this model shows that geographical distance reduce the effect of discriminatory trade liberalization in terms of relocation of modes supply strategy. The implication of geographical distance, which works as an additional dispersion, is that a reduction

\footnotetext{
${ }^{1}$ The proximity versus concentration hypothesis predicts that "firms are more likely to expand their production horizontally across borders the higher are the transport costs and trade barriers and the lower are investment barriers and the size of scale economies at the level at the plant level relative to the firm level" (Brainard, 1997).
} 
in trade costs (via a reduction in tariff) encourages both supply strategies, export and FDI, within as well as outside the economically integrated area. In the event of asymmetric trade liberalization, the existence of geographical frictions makes also the excluded country easier to reach: new exporters and affiliates will enter the excluded country. The implication of intrafirm trade is that it creates a correlation between trade and FDI. When countries belonging to the PTA are geographically remote, the complementarity relationship between export and FDI kicks in. This happens because, the fall in tariffs reduces the cost related to intra-firm trade so that the cost of FDI declines. This creates an advantage for export but also for FDI activities.

The literature on foreign direct investment and multinational corporations is vast. ${ }^{2}$ Previous models of "horizontal" FDI, conceive foreign subsidiary's sales as increasing with distance. Horstmann and Markusen (1992), develop a model in which market structure is determined endogenously as the outcome of firms' plant location decisions. They incorporated multinational firms (MNFs) into a general equilibrium trade model where firms benefit from internalization due to increasing returns at the firm level. Brainard (1993) develop a model of MNFs by focusing on the location decisions proposing the so-called proximity versus concentration hypothesis, or scale versus proximity. This hypothesis highlights the trade-off between reducing trade costs by locating near customers and concentrating production in only one location (which gives rise to scale economies at the plant level).

More recently, Helpman, Melitz and Yeaple (2004) (hereafter HMY), build a multi-country, multi-sectoral general equilibrium model with firm heterogeneity to analyse firms' decision to serve foreign markets either through exports or local sales (FDI). In these models, firms are more likely to be engaged in foreign direct investment (FDI) activities when trade costs are high. For the same reason, horizontal FDI is not encouraged by a reduction in trade costs. On the contrary, when trade costs fall, scale economies can outweigh the benefit from locating near customers. In this case, export activities are more profitable. Hence, the proximity versus concentration hypothesis predicts that the fall in trade costs should reduce FDI and encourage exports.

Comparing these theories with the empirical evidence on FDI, we discover that the spatial distribution of affiliates is much richer than the scale versus proximity would predict. In fact, despite the reduction in trade costs across countries, empirical works show a consistent growth of FDI inflows (e.g. Bernard, Jensen and Schott (2007), Blonigen et al. (2007), Baltagi et al. (2006), Hanson, Mataloni and Slaughter (2001) among others). By introducing intra-firm trade and international trade and transport costs this paper gives a role to geography in altering the spatial distribution of economic activities. Our results enrich what the scale versus proximity model predicts. More specifically, here the extensive margin will be related to two elements: firm heterogeneity and intra-firm trade. As usual, firm heterogeneity makes the number of firms changing with trade liberalization. But what this paper will show is that since affiliates rely on imported intermediates, trade liberalization can encourage new affiliates to locate in the excluded country, and not only new exporters.

Few empirical works address the role of regional economic integration on multinationals' location decision. Focusing on different types of regional integration, Blomström and Kokko

\footnotetext{
${ }^{2}$ See Barba-Navaretti and Venables (2004) for a survey on MNFs and empirical findings.
} 
(1997) study how PTA affects inward and outward FDI flows in the integrating region. ${ }^{3}$ Baltagi et al. (2008) consider bilateral outward FDI stocks into Europe. Their findings indicate a relocation of FDI from other countries to PTA members. Chen (2009) shows that integrated areas attract MNFs activity when characterized by access to a large size of markets. Antras and Foley (2011) build on the work of HMY, but focusing only on MNFs, to analyse the behavior of U.S. MNFs as a consequence of the signing of the ASEAN FTA.

This paper contributes to the literature by investigating the role of a PTA in shaping the spatial distribution of firm's activity, highlighting the differences between export and FDI. The novelty of this analysis is to combine different geographical spaces with FDI and export decisions. To study how market access strategies respond to changes in level of integration, we propose a general equilibrium model that features firm heterogeneity, trade and FDI. Since both types of activities imply crossing the border, trade and transport costs will apply to both exporting and FDI firms. Exporting firms export a finished good. Differently, foreign affiliates need to import a specific intermediate from their headquarters so to sell in loco a finished good. We can think of this imported intermediate as knowledge transfer to the foreign affiliate.

The diffusion of knowledge is at the heart of modern theories of growth and international trade. In this respect, this paper is also related to the model of knowledge transfer proposed by Yeaple and Keller (2012). In this study, the authors explain the labor market effects of offshoring in terms of the firms' ability to transfer knowledge abroad. Borrowing from them the concept knowledge transfer, the novelty of this paper stands in determining the spatial distribution of firm exports and multinational activity in the presence of intra-firm trade and different geographical spaces.

The rest of the paper is organized as follows. Section 2 presents the model. Section 3 characterizes its general equilibrium. Section 4 considers the effects of PTA on supply mode decisions considering different spatial networks. Section 5 considers the welfare effects of trade liberalization and, the last section concludes.

\section{Theoretical Framework}

To examine the implications of preferential trade agreements on supply strategies, we first propose a multi-country symmetric framework which accounts for both FDI and export mode decisions. Then we introduce the role of regional integration.

\subsection{Preferences}

Consumers in each country share the same preferences over two final goods: a homogeneous good, $h$, and a differentiated good, x. We assume a two-tier preference with Cobb-Douglas in the upper tier and CES in the lower tier. A fraction of income, $\beta$, is spent on the differentiated good, $c(v)$, and the rest $(1-\beta)$ is spent on the homogeneous good, $h$. The utility function is

$$
U=h^{(1-\beta)}\left[\int_{v \in V} c(v)^{(\sigma-1) / \sigma} d v\right]^{\frac{\sigma \beta}{\sigma-1}}
$$

\footnotetext{
${ }^{3}$ They find that the U.S.-Canada Free Trade Agreement led to a reduction in intra-regional FDI to both the integrated area while it increased extra-regional FDI into Canada.
} 
where $\sigma>1$ represents the elasticity of substitution between any two products within the group and $V$ is the set of available varieties.

\subsection{Supply}

There are $\mathrm{N}$ potentially asymmetric countries. We denote trade and transport costs between markets $\tau$ and $d$ respectively. In this framework we have two final goods, two intermediate goods and one factor. Each country is endowed with labour, L, which is supplied inelastically.

There are two sectors, one homogeneous and one differentiated. The homogeneous sector produces a homogeneous good, $h$, with constant returns to scale and perfect competition which is freely traded on international markets. In this sector the technology is simple. We choose units of $h$ such that one unit of labour is required per unit of output. Therefore, the unit cost function is $w$, where $w$ is the wage rate for labour. This unit cost function represents marginal and average costs. In the homogeneous sector, competition ensures price equal marginal costs, $p_{h}=w$. It is convenient to choose good $h$ as the numeraire, so that $p_{h}=1$; hence, the pricing condition becomes: $1=w$. We take $\beta$ to be small enough and differences in labor supply, $L$, to be small enough so that the homogeneous product is produced in every country and wages are equalized across countries. ${ }^{4}$

The differentiated sector produces a continuum of horizontally differentiated varieties, $x(v)$, from two intermediate goods (or tasks), $y_{1}$ and $y_{2}$. Both $y_{1}$ and $y_{2}$ are produced with one unit of labour. The particular production structure of foreign affiliates requires intermediate $y_{1}$ to be made by the headquarter, due to technological appropriability issues. Since both types of activities imply crossing the border, trade and transport costs apply to exporting and FDI firms. Exporting firms export a finished good. Differently, foreign affiliates import a specific intermediate from their headquarters and sell in loco a finished good. Each variety produced in the differentiated sector is then supplied by a Dixit-Stiglitz monopolistically competitive firm which produces under increasing returns to scale which arise from a fixed cost.

Foreign affiliates production relies on the essential intermediate good $y_{1}$ produced in the home headquarter due, say, to issues of intellectual property protection, the need for highly specialised employees, or even overwhelming scale economies that makes production of the intermediate in a single plant the optimised outcome. This imported intermediate within the boundaries of the firm can be considered as knowledge transfer to the foreign affiliate. This knowledge transfer is a well established fact in the $R \& D$ literature. This transfer of intermediate goods allow to create a strong positive correlation between trade and FDI.

Three modes of supply characterize the $x$-sector; firms which sell only domestically (Dmode); firms who export (X-mode), and firms who supply the foreign market via FDI (Mmode). Hence, when a firm decides to serve the foreign market, it chooses whether to export domestically produced goods or to produce in foreign via affiliate production. Differently from the HMY set up, in this paper geographical distance plays a crucial role in characterizing intra-firm trade. ${ }^{5}$ More specifically, the fact that foreign affiliates need to import $y_{1}$ from their home headquarters plays an important role. If a firm chooses to supply the foreign market via local sales of its affiliates, these affiliates must import the intermediate good $y_{1}$ from the home

\footnotetext{
${ }^{4}$ The value of $\beta$ is chosen to satisfy the assumption of no black holes.

${ }^{5}$ In HMY the export versus MNFs choice is affected by the classical scale versus proximity trade-off.
} 
nation. Since the M-mode does not entirely avoid trade costs, export and FDI activities can here become complements: trade liberalization increases both types of mode of supply.

Entering the $x$ sector involves a fixed variety-development cost $f_{I}{ }^{6}$ Subsequently, each entrant draws a labour per unit output coefficient (called $a$ ) from a cumulative density function $G(a)$ that is common to every country. The support of the continuous random variable $a$ is $0 \leq a \leq a_{0}$. Upon drawing its own parameter $a$, each firm decides to exit (if it has a low productivity draw), or to produce. In this case, the firm must face additional fixed costs linked to the mode of supply chosen. If it chooses to produce for its own domestic market, it pays the additional fixed market entry cost, $f_{D}$. If the firm chooses to export, it bears the additional costs $f_{X}$ of meeting different market specific standards (e.g. the cost of creating a distribution network in a new country). Finally, if the firm chooses to serve foreign markets through FDI, it incurs in the fixed cost of creating a distribution network as well as building up new capacities in the foreign country, $f_{M}$.

As mentioned, the homogeneous sector is not subject to trade costs, but the differentiated sector is subject to both trade and transport costs (iceberg type). More precisely, in the Xmode case, the entire final good is subject to trade and transport costs, while with M-mode only the intermediate good $y_{1}$ is subject to those costs. Selling one unit in the destination market $j$, would require shipment from the origin country $i$ of $d_{i j} \tau_{i j} \geq 1$ units for the exporting firms and $\left(d_{i j} \tau_{i j}\right)^{\eta}$ for the FDI firms, where $d_{i j}$ represents the transport barriers, $\tau_{i j}$ the trade cost and $\eta$ the share of intermediate good used in final production.

\section{$2.3 \quad$ Intermediate Results}

\subsubsection{Demand}

Given preferences across varieties have the standard CES form, the demand function is,

$$
x_{i}(v)=A_{i} p_{i}(v)^{-\sigma} \text { where } A_{i} \equiv \frac{\beta E_{i}}{P_{i}^{1-\sigma}}
$$

where we set $i$ for origin and $j$ for destination. Thus, $x_{i}(v)$ represents the consumption of typical variety $v, A_{i}$ is the demand shifter and finally $p_{i}(v)$ is the consumer price index of variety $v . A_{i}$ is exogenous from the perspective of the firm and composed by the aggregate level of spending on the differentiated good in the origin country, $\beta E_{i}$ divided by the CES price index, $P_{i}^{1-\sigma}$. The inverse demand function is given by

$$
p_{i}(v)=A_{i}^{\frac{1}{\sigma}} x_{i}(v)^{-\frac{1}{\sigma}}
$$

\subsubsection{Organization and Product Variety}

Given that $f_{I}$ has been paid, the output of every variety is described by a Cobb-Douglas function of the intermediate goods,

$$
x_{i}(v)=\frac{1}{a(v)}\left(\frac{y_{1}}{\eta}\right)^{\eta}\left(\frac{y_{2}}{1-\eta}\right)^{1-\eta}, 0<\eta<1
$$

\footnotetext{
${ }^{6}$ The subscript $I$ stands for innovation.
} 
where $1 / a(v)$ represents the firm specific productivity parameter and $\eta$ is the Cobb-Douglas cost share of $y_{1}$, common across all nations. When trade is possible, firms that produce decide whether to supply a particular market and how, i.e. via export or FDI strategies. This depends on their own productivity and on the distance between the origin and the destination country. The marginal costs for the exporting firms is thus higher than the one for the FDI firms.

Since $y_{1}$ and $y_{2}$ are produced with $L$ whose wage is unity, the marginal costs, $m c_{D i}$, for local production in every origin country is the following,

$$
m c_{D i}=a(v)
$$

The marginal cost for exporting to the destination market is linear in $d \tau$,

$$
m c_{X i j}=a(v) d_{i j} \tau_{i j}
$$

where $d_{i j}$ and $\tau_{i j}$ represent transport and trade cost respectively between origin and destination countries. Finally, the marginal cost for supplying the destination market via local sales of foreign affiliates is concave in $d_{i j} \tau_{i j}$,

$$
m c_{M i j}=a(v)\left(d_{i j} \tau_{i j}\right)^{\eta}
$$

Note that in this last marginal cost distance matters but only in relation to cost share, $\eta$, of the intermediate good $y_{1}$ used in the production of the final good. Using the mark up, $\sigma /(\sigma-1)$, we can easily derive the price for each particular mode of supply decisions. ${ }^{7}$

\subsubsection{Mode of Supply Decisions}

The mode of supply decision choice involves the comparison of profit levels taking into account the various fixed and variable trade costs. A firm can decide to: (i) not supply a market, (ii) supply it via exports, or (iii) supply it via local sales of foreign affiliates. Of course, the local market is supplied by local sales, if the firm is active $(i v)$.

Firm's productivity determines the optimal mode of supply. As described above, four cases are relevant.

Case $(i)$. If the firm decides not supply a market and exits, the operating profits are zero.

Case $(i i)$. If the firm decides to supply a market via exports, the profits from exporting to the $j$ market are linearly decreasing in $d$ and $\tau$,

$$
\pi_{X i j}=\left[p_{X i j}(v)-a(v) d_{i j} \tau_{i j}\right] x_{i j}(v)_{X}-f_{X}
$$

where $x_{i j}(v)$ represents the quantity exported to country $j$.

Case (iii). If the firm decides to supply a market via FDI, the profits realized by a subsidiary located in the destination market depend on the interaction between $d$ and $\tau$,

$$
\pi_{M i j}=\left[p_{M i j}(v)-a(v)\left(d_{i j} \tau_{i j}\right)^{\eta}\right] x_{i j}(v)_{M}-f_{M}
$$

where $\left(d_{i j} \tau_{i j}\right)^{\eta}$ is the distance and trade costs associated with the intermediate good, $y_{1}$,

\footnotetext{
${ }^{7}$ See appendix A for details of the cost minimization problem.
} 
imported from the home country and $x_{i j}(v)_{M}$ is the quantity supplied by the foreign subsidiary in country $j$.

Case (iv). If the market under consideration is the firm's home market, the profits from undertaking D-mode supply are

$$
\pi_{D i}(v)=\left[p_{D i}(v)-a(v)\right] x(v)_{i}-f_{D}
$$

where $x(v)_{i}$ represents the quantity supplied in the domestic market.

Using the intermediate results from consumers and firms optimization problems we calculate the operating profit for the three modes of supplying a market. ${ }^{8}$ The profit from serving the domestic market is a function of the demand shifter and the constant mark-up,

$$
\pi_{D i}^{*}(a, A, \eta)=A_{i} a^{1-\sigma} \frac{1}{\sigma}\left(\frac{\sigma}{\sigma-1}\right)^{(1-\sigma)}-f_{D}
$$

where $A_{i}$ and $\eta$ are industry (and so country) specific. Using $B_{i}=\frac{A_{i}}{\sigma}\left(\frac{\sigma}{\sigma-1}\right)^{(1-\sigma)}$ we obtain:

$$
\pi_{D i}^{*}(a, A, \eta)=B_{i} a^{1-\sigma}-f_{D}
$$

If a firm chooses the X-mode for a given foreign market, then its equilibrium net operating profit on sales in that market is

$$
\pi_{X i j}^{*}(a, A, \eta)=B_{j}\left(d_{i j} \tau_{i j} a\right)^{1-\sigma}-f_{X}
$$

where $B_{j}=\frac{A_{j}}{\sigma}\left(\frac{\sigma}{\sigma-1}\right)^{(1-\sigma)}$. If a firm chooses the M-mode for a given foreign market, then the equilibrium net operating profit it would earn is

$$
\pi_{M i j}^{*}(a, A, \eta)=B_{j} a^{1-\sigma}\left[\left(d_{i j} \tau_{i j}\right)^{\eta}\right]^{1-\sigma}-f_{M}
$$

To focus on the central case, we set parameters so to get the same ranking as in HMY when there are only two nations. Namely, firms with sufficiently high productivity will supply the foreign market at all, with the most productive supplying it via FDI rather than exports. In this way our model is in line with the HMY empirical findings. Hence, the regularity condition we need is,

$$
f_{D}<\left(d_{i j} \tau_{i j}\right)^{(\sigma-1)} f_{X}<\left(d_{i j} \tau_{i j}\right)^{\eta(\sigma-1)} f_{M}
$$

\footnotetext{
${ }^{8}$ The operating profit equations are indicated with stars.
} 
To clarify the analysis, we represent the profit functions discussed above with the help of Figure 1.

Figure 1: Profits and Foreign Markets

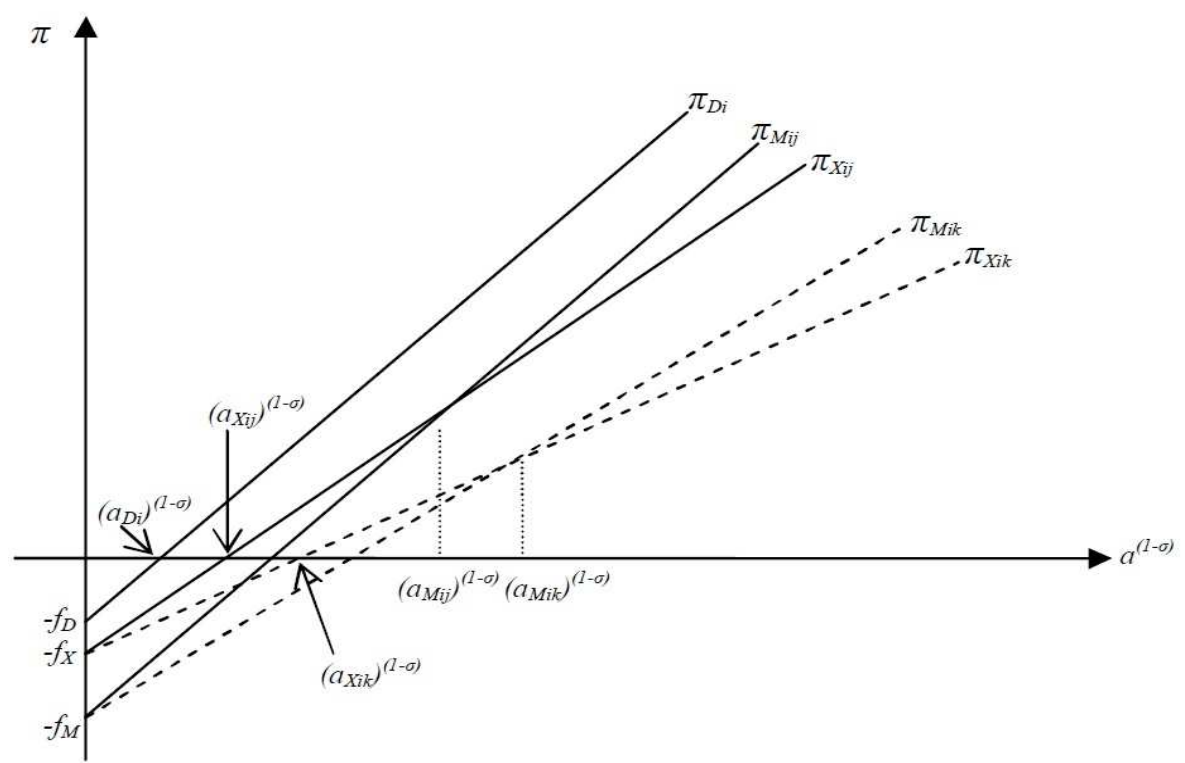

Figure 1 shows how trade and transport costs affects the modes of supply from country $i$ to destinations $j$ and $k$, with this latter more remote than $j$. On the horizontal axis we have $a^{1-\sigma}$; since $\sigma>1$, this variable can be used as a firm-level productivity index. All the profits described in (7), (8) and (9) are increasing functions of $a^{1-\sigma}$. In the model, $a_{X}^{1-\sigma}$ always rises with space and trade costs. We cannot say the same for $a_{M}^{1-\sigma}$. In fact, $a_{M}^{1-\sigma}$ has an ambiguous behaviour with respect to space and trade costs. Nevertheless for the sake of simplicity, Figure 1 accounts for a FDI cutoff productivity which is increasing with trade and transport costs.

The profit function $\pi_{M i j}$ is slightly flatter than $\pi_{D i}$, due to trade and transport costs. For what concern the profits for reaching destination $k$, in this case, the slope of $\pi_{M i k}$ is flatter than $\pi_{M i j}$, this because $\left[\left(\tau_{i k} \gamma_{i k}\right)^{\eta}\right]^{1-\sigma}<\left[\left(\tau_{i j} \gamma_{i j}\right)^{\eta}\right]^{1-\sigma}$. Profit functions for exporting firms behave similarly to HMY (2004). Since the FDI supply mode incurs in trade and transport costs for intermediate $y_{1}, \pi_{M i j}$ is steeper than $\pi_{X i j}$. Depending on space and trade costs, there exist different productivity thresholds for export or FDI strategy.

\subsection{Equilibrium Conditions}

\section{The Cutoff Conditions}

Firms choose the optimal supply mode for each market. To relate this choice to firms' marginal costs we define a threshold marginal cost, $a(v)$, for each destination and for each mode of supply. Using the equilibrium operating profit of serving the domestic market from (7), we derive the domestic cutoff condition,

$$
a_{D i}=\left(\frac{f_{D}}{B_{i}}\right)^{\frac{1}{1-\sigma}}
$$


That is, firms with $a(v)$ below $a_{D i}$ will find it optimal to supply their local market; firms with $a(v)>a_{D i}$ will expect negative profits and exit the industry.

The choice in foreign markets is more complex. The net operating profits of supplying the foreign market $j$ rise under both modes of supply. Firms with $a_{X i j}<a(v)<a_{D i}$ have positive operating profits from sales in the domestic market, but they lose money if they choose to supply foreign markets. Using the net operating profit from exporting (8), we can derive the X-mode cutoff,

$$
a_{X i j}=\left(\frac{f_{X}}{B_{j}\left(d_{i j} \tau_{i j}\right)^{1-\sigma}}\right)^{\frac{1}{1-\sigma}}
$$

Only firms with $a(v) \leq a_{X i j}$ will consider export to the $j$ market.

Notice that at $a(v)=a_{X i j}$ exporting yields a higher net operating profit then FDI. This ordering switches, however, for firms with $a(v) \leq a_{M i j}$, where this is defined as the $a(v)$ where:

$$
a_{M i j}=\left(\frac{f_{M}-f_{X}}{B_{j}\left[\left(d_{i j} \tau_{i j}\right)^{\eta(1-\sigma)}-\left(d_{i j} \tau_{i j}\right)^{1-\sigma}\right]}\right)^{\frac{1}{1-\sigma}}
$$

This M-mode cutoff is obtained by equating the operating profits from doing FDI, (9), with the operating profit from doing export, (8). This is because by construction, a firm chooses to supply market $j$ via FDI if and only if the FDI strategy is more profitable than the export strategy, i.e. if this holds:

$$
\pi_{M i j}-\pi_{X, i j} \geq f_{M}-f_{X}
$$

which can be rewritten as,

$$
B_{j} a_{M i j}^{1-\sigma}\left[\left(d_{i j} \tau_{i j}\right)^{\eta(1-\sigma)}-\left(d_{i j} \tau_{i j}\right)^{1-\sigma}\right]=f_{M}-f_{X}
$$

Notice that if $a(v) \leq a_{M i j}$, M-mode supply yields a higher net operating profit.

This set up is initially used to briefly explore the properties of the symmetric equilibrium. Then it will be our point of departure to evaluate the role of different spatial networks on preferential trade agreements.

\section{General Equilibrium in the Symmetric Case}

This section presents general equilibrium results for the perfectly symmetric case, $i=j$. Since we are in the symmetric case, the expressions below are reported without subscripts $i$ and $j$. Using the price index, solved assuming the Pareto distribution, inside the domestic cutoff condition (10), we find the equilibrium number of varieties (and so the number of all firms competing in that country) consumed in a typical nation: ${ }^{9}$

$$
n^{*}=\frac{(b-1) \beta E}{\sigma b f_{D}\left[1+T^{1-b}(N-1)(\phi \gamma)^{b}+V^{1-b}(N-1)\left((\phi \gamma)^{\eta}-\phi \gamma\right)^{b}\right]}
$$

\footnotetext{
${ }^{9}$ Appendix B provides further details on price index and free entry solved assuming a Pareto distribution, i.e. equations (29) and (30) respectively.
} 
where $b=\frac{k}{\sigma-1} ; \phi=\tau^{1-\sigma} ; \gamma=(d)^{1-\sigma} ; T=f_{X} / f_{D}$ and $V=\left(f_{M}-f_{X}\right) / f_{D}$.

We set $\Omega=T^{1-b}(N-1)(\phi \gamma)^{b}$, and, $\Psi=V^{1-b}(N-1)\left[(\phi \gamma)^{\eta}-\phi \gamma\right]^{b}$. Where the parameters $\Psi$ and $\Omega$ summarize the impact of the two types of trade barriers on exports and on FDI activities. More specifically, $\Omega$ represents the combined effect of higher fixed and variable costs on the export strategy. While $\Psi$ measures the relative fixed and variable costs of FDI strategy. Using $\Psi$ and $\Omega$, the expression for $n^{*}$ could be then simplified to:

$$
n^{*}=\frac{(b-1) \beta E}{\sigma b f_{D}[1+\Omega+\Psi]}
$$

The equilibrium number of firms described by (14) represents the actual number of survivors in each country, which decreases with $\Psi$ and $\Omega$, hence it decreases with higher fixed and variable costs.

Using the free entry condition and price index solved assuming a Pareto distribution, and the ratio between cutoff conditions, (11) and (10) as well as (12) and (10), we get explicit closed form solutions for $a_{D}, a_{X}$, and $a_{M}$. In particular,

$$
a_{D}^{*}=a_{0}\left[\frac{(b-1) f_{I}}{\left(f_{D}(1+\Psi+\Omega)\right)}\right]^{\frac{1}{k}}
$$

Using (15) inside the ratio between (11) and (10) we find:

$$
a_{X}^{*}=a_{0}\left[\frac{(b-1) f_{I}}{f_{X}(1+\Psi+\Omega)}(\phi \gamma)^{b} T^{1-b}\right]^{\frac{1}{k}}
$$

Finally, using (15) inside the ratio between (12) and (10) we obtain the equilibrium cutoff for the M-mode:

$$
a_{M}^{*}=a_{0}\left[\frac{(b-1) f_{I}}{(1+\Psi+\Omega)}\left[(\phi \gamma)^{\eta}-(\phi \gamma)\right]^{b} \frac{V^{1-b}}{f_{M}-f_{X}}\right]^{\frac{1}{k}}
$$

Comparative statics on equations (15)-(17), points out interesting results. The costs of doing export and FDI, i.e. $\Psi$ and $\Omega$, decline with trade liberalization. Nevertheless, if export activities are unambiguously boosted, the way in which FDI activities are affected is more complex. While the the ratios of the fixed costs stay the same, the marginal cost of exporting decreases more than the marginal cost of FDI (this latter decreases $\eta$ times the reduction in trade costs). Therefore, what allows FDI to become more or less attractive is strictly related to trade and transport barriers and to the share of imported input in production. Overall, since more firms will be able to reach the foreign market, this increases competition which leads to an increase in the average productivity ( $a_{D}$ declines).

Result 1: Trade liberalization forces the least productive firms to exit, generates the entrance of new firms into the export markets and can discourage FDI activity. Export and FDI activities are substitute activities for low trade and transport frictions, i.e. low $\tau$ and $d$.

Proof. See Appendix C.

These results are obtained assuming a perfectly symmetric scenario. Despite the existence of $\mathrm{N}$ countries, we are not yet considering how geographical space is affecting the supply mode 
decisions within the same firm and across countries. To precisely characterize the relationship between export and FDI while accounting for third country effects, we need to compare different geographical frameworks. Discriminatory trade policy (PTAs) as well as geographical space, will thus be the focus of the following section. We will show how increased exposure to trade generates the entry of both new exporters as well as new FDI firms when geographical space plays a role.

\section{Spatial Networks and Preferential Trade Agreements}

To give a role to discriminatory trade policy, we need to go beyond the two country location. In what follows, we establish the role of a PTA in shaping the spatial distribution of firm's activity, while allowing for different geography structures.

In a two country model, the relative position of each one of the countries is irrelevant. But when more countries are considered, and trade costs are not symmetric, accounting for their relative position becomes crucial. We thus assume that the world is composed by three economies. In this set up, we analyse how different geographical spaces interact with asymmetric liberalization (PTA) in determining the volume and the extent of firms' supply strategy.

Two types of spatial structures are considered. The first representation relies on the Euclidean distance between different countries located on a line segment. Then to eliminate cross country differences in centrality, we consider a geographical structure in which countries are evenly spaced around a circle so that shipping between any two locations takes place through the center. These two structures allows us to analyse how changes in trade frictions affect countries' distribution of economic strategy.

Our three countries framework is composed by $i, j$ and $z$. With respect to the symmetric situation explored in section 3, we now solve for a new equilibrium in which asymmetric trade integration, PTA, exists between country $i$ and $j$. Notice that countries are pairwise symmetric, thus $i j=j i$ and $i z=z i$. The PTA between $i$ and $j$ implies that trade costs are such that $\tau_{i j}<\tau_{i z}$. After solving for this asymmetric equilibrium, we then evaluate, in the two possible geographical spaces, what happens when the level of integration increases (i.e. decrease in $\tau_{i j}$ ).

\subsection{General Equilibrium in the Asymmetric Case}

In what follows we propose the benchmark case, such as preferential trade liberalization without assuming any particular geographical structure. Notice that symmetry is preserved between country $i$ and $j$. This implies that the new model to be solved has eight cutoffs, two free entry conditions and two price indices.

\section{Free Entry}

In order to characterize the general equilibrium results for the asymmetric case, we specify the two free entry conditions and the two price indices. The free entry condition for firms in country $z$ is defined as follows: 


$$
\int_{0}^{a_{D z}} \pi_{D}^{z} d G(a)+2 \int_{a_{M z i=j}}^{a_{X z i=j}} \pi_{X}^{i=j} d G(a)+2 \int_{0}^{a_{M z i=j}} \pi_{M}^{d} d G(a)=f_{I}
$$

where $z$ and $i$ are respectively the origin and the destination country. Note that the cutoffs $a_{M z i}$ and $a_{X z i}$ represent the threshold marginal costs for country $z$ 's FDI and exporting firms respectively.

The free entry condition for firms in country $i$ is defined as:

$$
\int_{0}^{a_{D i}} \pi_{D}^{i} d G(a)+\int_{a_{M i j}}^{a_{X i j}} \pi_{X}^{j} d G(a)+\int_{a_{M i z}}^{a_{X i z}} \pi_{X}^{z} d G(a)+\int_{0}^{a_{M i j}} \pi_{M}^{j} d G(a)+\int_{0}^{a_{M i z}} \pi_{M}^{z} d G(a)=f_{I}
$$

Note that the cutoffs $a_{M i j}$ as well as $a_{M i z}$ represent the threshold marginal costs for country $i$ 's FDI firms; while $a_{X i j}$ as well as $a_{X i z}$ represent the threshold marginal costs for country $i$ 's exporting firms. ${ }^{10}$

\section{Price Index}

The price index of the final good in country $z$ is defined as:

$$
\begin{aligned}
P_{z}^{1-\sigma}=\left(\frac{\sigma}{\sigma-1}\right)^{1-\sigma}\left[n_{z} \int_{0}^{a_{D z}} a^{1-\sigma} d G\left(a / a_{D z}\right)+\right. \\
\left.\quad+2 n_{i}\left(\phi_{i z} \gamma_{i z} \int_{a M i z}^{a_{X i z}} a^{1-\sigma} d G\left(a / a_{D i}\right)+\left(\phi_{i z} \gamma_{i z}\right)^{\eta} \int_{0}^{a_{M i z}} a^{1-\sigma} d G\left(a / a_{D i}\right)\right)\right]
\end{aligned}
$$

Similarly, the price index for the final good in country $i$ is:

$$
\begin{gathered}
P_{i}^{1-\sigma}=\left(\frac{\sigma}{\sigma-1}\right)^{1-\sigma}\left[n_{i}\left(\int_{0}^{a_{D i}} a^{1-\sigma} d G\left(a / a_{D i}\right)+\phi_{i j} \gamma_{i j} \int_{a M i j}^{a_{X i j}} a^{1-\sigma} d G\left(a / a_{D i}\right)+\left(\phi_{i j} \gamma_{i j}\right)^{\eta} \int_{0}^{a_{M i j}} a^{1-\sigma} d G\left(a / a_{D i}\right)\right)\right) \\
\left.+n_{z}\left(\phi_{i z} \gamma_{i z} \int_{a M i z}^{a_{X i z}} a^{1-\sigma} d G\left(a / a_{D i}\right)+\left(\phi_{i z} \gamma_{i z}\right)^{\eta} \int_{0}^{a_{M i z}} a^{1-\sigma} d G\left(a / a_{D i}\right)\right)\right]
\end{gathered}
$$

\section{Comparative Statics for Asymmetric Case}

In this part we provide comparative statics for the benchmark case described above where no particular geographical structure is assumed. More specifically, we study how the equilibrium cutoffs are affected by deeper asymmetric trade liberalization, expressed as higher trade openness between $i$ and $j$ (increase in $\phi_{i j}$ ). Our set up considers countries $i$ and $j$ as perfectly symmetric and different from country $z$ in terms of trade integration. The system to be solved involves eighteen equations (fifteen cutoffs and the number of firms in each country). However, due to the symmetry between $i$ and $j$, the system reduces to eight cutoffs and two number of firms, $n_{i}$ and $n_{z}$.

\footnotetext{
${ }^{10}$ Appendix D provides these free entry conditions solved assuming a Pareto distribution.
} 
Let's start with analyzing the domestic cutoffs in those countries belonging to the PTA, $i=j$, and in the excluded one, $z$. The partial derivatives are:

$$
\frac{\partial a_{D i}}{\partial \phi_{i j}}=\frac{\partial}{\partial \phi_{i j}}\left(\frac{f_{D}}{B_{i}}\right)^{\frac{1}{1-\sigma}} \text { and } \quad \frac{\partial a_{D z}}{\partial \phi_{i j}}=\frac{\partial}{\partial \phi_{i j}}\left(\frac{f_{D}}{B_{z}}\right)^{\frac{1}{1-\sigma}}
$$

The sign of these derivatives depend on the behavior of the demand level in each of the origin country, $B_{i}$ and $B_{z} \cdot{ }^{11}$ Notice that $B_{i}$ is a collection of terms; its behavior reflects movement into the price index $P_{i}$ (the same for country $z$ ). Further integration between country $i$ and $j$ implies a reduction in their price index due to larger competition. Using the relationship linking $P_{i}$ to $B_{i}$, this generates an inverse relationship between $B_{i}$ and $\phi_{i j}$. Therefore, since $B_{i}$ is decreasing with $\phi_{i j}$, the derivative of the domestic cutoff is unambiguously negative for countries belonging to the PTA. Countries $i$ and $j$ are experiencing an increase in their average productivity. Differently, further integration between country $i$ and $j$ implies an increase in the price index of the excluded $z$-country, $P_{z}$, due to reduced competition. This effect is due to the trade diversion imposed by the PTA between $i$ and $j$. Thus, there is a positive relationship between $B_{z}$ and $\phi_{i j}$. The derivative of the domestic cutoff in country $z$ is unambiguously positive and average productivity is here declining.

Comparative statics on the exporting cutoffs implies:

$$
\begin{gathered}
\frac{\partial a_{X i j}}{\partial \phi_{i j}}=\frac{\partial}{\partial \phi_{i j}}\left(\frac{f_{X}}{B_{j}\left(\phi_{i j} \gamma_{i j}\right)}\right)^{\frac{1}{1-\sigma}} \\
\frac{\partial a_{X i z}}{\partial \phi_{i j}}=\frac{\partial}{\partial \phi_{i j}}\left(\frac{f_{X}}{B_{z}\left(\phi_{i z} \gamma_{i z}\right)}\right)^{\frac{1}{1-\sigma}} \\
\frac{\partial a_{X z i}}{\partial \phi_{i j}}=\frac{\partial}{\partial \phi_{i j}}\left(\frac{f_{X}}{B_{i=j}\left(\phi_{i z} \gamma_{i z}\right)}\right)^{\frac{1}{1-\sigma}}
\end{gathered}
$$

The sign of the above derivatives depend on the two terms in the denominator, the demand levels, $B$ 's, and $\phi_{i j} \gamma_{i j}$. We established before that as a consequence of integration between $i$ and $j, B_{z}$ is increasing while $B_{i=j}$ is decreasing. In the integrated area, the combined effect of $B_{i=j}$ and $\phi_{i j} \gamma_{i j}$ makes the export cutoff, $a_{X i j}$, increasing due to the reduction in export costs. Similarly entering in country $z$ is easier for firms belonging to the integrated area. This is due to the reduced competition, reflected into an increasing $B_{z}$ which lead to an increased $a_{X i z}$. Overall, the PTA allow more country $i$ 's firms to become exporters in both $j$ and $z$.

On the contrary, deeper integration between $i$ and $j$ decreases the export cutoff required for $z$-firms to export in the integrated area, $a_{X z i}$. As we see from equation in (23c), only the term $B_{i=j}$ is changing after the PTA between $i$ and $j$. Since $B_{i}$ is decreasing, but trade and transport barriers are left unchanged, $a_{X z i}$ decreases as well. Due to the exclusion effect, the export productivity threshold required to enter market $i$ from country $z$ has increased. Marginal cost of export is thus decreasing for firms in the excluded area, while it increases for firms in the integrated area.

We now consider comparative statics on equilibrium cutoffs for firms accessing the foreign

\footnotetext{
${ }^{11}$ See Appendix D for further details on $B_{i}$ and $B_{z}$.
} 
market via FDI,

$$
\begin{aligned}
\frac{\partial a_{M i j}}{\partial \phi_{i j}} & =\frac{\partial}{\partial \phi_{i j}}\left(\frac{f_{M}-f_{X}}{B_{j}\left[\left(\phi_{i j} \gamma_{i j}\right)^{\eta}-\phi_{i j} \gamma_{i j}\right]}\right)^{\frac{1}{1-\sigma}} \\
\frac{\partial a_{M i z}}{\partial \phi_{i j}} & =\frac{\partial}{\partial \phi_{i j}}\left(\frac{f_{M}-f_{X}}{B_{z}\left[\left(\phi_{i z} \gamma_{i z}\right)^{\eta}-\phi_{i z} \gamma_{i z}\right]}\right)^{\frac{1}{1-\sigma}} \\
\frac{\partial a_{M z i}}{\partial \phi_{i j}} & =\frac{\partial}{\partial \phi_{i j}}\left(\frac{f_{M}-f_{X}}{B_{z}\left[\left(\phi_{i z} \gamma_{i z}\right)^{\eta}-\phi_{i z} \gamma_{i z}\right]}\right)^{\frac{1}{1-\sigma}}
\end{aligned}
$$

The sign of these derivatives depend on the behaviour of $B_{i}, B_{z}$ and $\left[\left(\phi_{i j} \gamma_{i j}\right)^{\eta}-\phi_{i j} \gamma_{i j}\right]$. Equation (24a) reveals that the reaction of the FDI cutoff to $\phi_{i j}$ is ambiguous and depends on the combined effect between what happens to $B_{j}$ and to $\left[\left(\phi_{i j} \gamma_{i j}\right)^{\eta}-\phi_{i j} \gamma_{i j}\right]$. Equations (24b) and $(24 \mathrm{c})$ are instead unambiguous.

Considering equation (24a), it is easy to verify that its sign depend on $\frac{\partial\left[\left(\phi_{i j} \gamma_{i j}\right)^{\eta}-\left(\phi_{i j} \gamma_{i j}\right)\right]^{b}}{\partial \phi_{i j}}{ }^{12}$ This implies that $\eta \gamma_{i j}^{\eta-1} \phi_{i j}^{\eta-1}$ is crucial in determining the sign of $(24 \mathrm{a})$. If $\eta \gamma_{i j}^{\eta-1} \phi_{i j}^{\eta-1}<1$, thus if trade and transport frictions are sufficiently small in size, there is a selection among firms entering via FDI (equation 24a is negative). When this is true, FDI mode of supply from country $i$ acts as a substitute for export. A reduction in trade cost does not make intra-firm trade sufficiently convenient to choose the FDI mode of supply. This result is always true when we will analyze the PTA by eliminating cross country differences in centrality in Section 4.3. In this case, the FDI cutoff productivity for firms in countries $i$ and $j$ is increasing. Differently, when trade and transport frictions are large enough, equation (24a) becomes positive. Therefore, a reduction in trade cost makes intra-firm trade more convenient so that more firms choose the FDI mode of supply. This is what happens when country z is geographically included but $i$ and $j$ are remote, as in Section 4.2 case B. In this case, $\eta \gamma_{i j}^{\eta-1} \phi^{\eta-1}$ is larger than one: transportation barriers between $i$ and $j$ are sufficiently high that the required productivity to engage in FDI is decreasing in $\phi_{i j}$ for firms in the integrated area.

There are no ambiguities for equations (24b) and (24c). The sign of equation (24b) is positive: $i$-firms enjoy easier access via FDI also in the excluded country ( $a_{M i z}$ is increasing) due to the spillover effect of deeper integration. Conversely, the sign of equation (24c) is negative: the FDI cutoff required for $z$-firms to open overseas affiliates in the integrated area, $a_{M z i}$, is unambiguously decreasing. This is due to the tougher competitive environment country- $z$ 's firms are facing when entering the integrated area.

Complementarity between export and FDI relies on similar reaction of export and FDI cutoffs to further degrees of integration. Thus, if the sign of equation (24a) is positive, export and FDI activities are complement for firms in the PTA. The behaviour of cutoffs generates implication on number of firms as well as on the intensity of their activities. ${ }^{13}$ Due to the complexity of analytical results for the asymmetric case, we need to solve the model numerically so to have a graphical understanding of the behaviour of the number of firms. ${ }^{14}$

\footnotetext{
${ }^{12}$ This result is related to the proof provided in Appendix C.

${ }^{13}$ Comparative statics on number of firms is provided in appendices $\mathrm{E}$ to $\mathrm{G}$.

${ }^{14}$ See Fujita et al. (1999) and Baldwin et al. (2003).
} 


\subsection{PTA in different geographical spaces}

This section analyses, in each geographical space, what happens to the location of economic activities when the level of integration increases. To examine the location of economic activities, we rely on numerical examples where specific parameter values are assigned. Values for the fixed costs are chosen so to satisfy the ranking condition among the three locations. Transport and non-transport measures are chosen in logarithm. The elasticity of substitution, $\sigma$, is taken from Broda and Weinstein (2006). For the period 1999-2001 they find average and median elasticity for SITC 5-digit goods is 13.1 and 2.7, respectively (see their table IV). The value we choose falls in the range of estimates of Broda and Weinstein (2006). The value of $\beta$ is chosen to satisfy the assumption of no black holes, such as $(\sigma-1) / \sigma>\beta$. To assign a value to $\eta$ we follow the findings in the literature and assign a magnitude of around $1 / 3$ to intra-firm trade. ${ }^{15}$

\subsubsection{Impact of changes in tariff frictions: triangle}

This section considers a linear representation of the geographical space to evaluate declining trade costs between countries $i$ and $j$, while keeping fixed frictions involving country $z$. A preferential trade liberalization event is here combined with different accessibility to foreign markets, i.e. $d_{i j} \neq d_{i z}$. Note that shipping from $i$ to $j$ (when $i$ and $j$ are adjacent) costs $\tau_{i j} \times d_{i j}$, whereas shipping to a third $z$-country costs $\tau_{i z} \times d_{i z}$.

This section distinguishes between two cases, A and B, according to the geographical position of country $z$ with respect to $i$. Since this section wants to show the impact of preferential liberalization on the localization of firms' activities, the comparative statics conducted will be related to changes in the number of exporting and FDI firms in the integrated region and in the excluded country.

Case A: Country $z$ is geographically isolated, i.e. $d_{i j}<d_{i z}=d_{j z}$.

Case A considers the effect of a PTA when country- $z$ is not only excluded from the economic integration but also geographically disadvantaged. Starting from a benchmark equilibrium in which country- $z$ is geographically isolated and excluded from the PTA, we consider the effects of increasing level of integration between $i$ and $j$, i.e. increase in $\phi_{i j}$. Due to the geographical exclusion of country $z$, the FDI cutoff for firms belonging to the PTA area is here characterized by a non monotonic behavior with respect to an increase in $\phi_{i j} .{ }^{16}$

The increase in competition reduces the number of active firms in the integrated area, the reverse is true for active firms in country $z$. For low level of trade integration (low $\left.\phi_{i j}\right)$, the number of $i$ - and $j$ - exporters and overseas affiliates increases after the PTA both in the integrated area and in the excluded country. Nevertheless, for higher levels of trade integration (high $\phi_{i j}$ ) the increase in the number of overseas affiliates within the integrated area, turns into a decline. ${ }^{17}$ Further integration between $i$ and $j$ (increase in $\phi_{i j}$ ) encourages exporters at the expenses of FDI activity. Despite the increase in openness, FDI activity remains so expensive, that only the export activity is prompt. The opposite result is true for country $z$ : preferential trade liberalization reduces the number of $z$-firms that can enter as exporters

\footnotetext{
${ }^{15}$ Choosing different values for $\sigma$ and $\eta$ did not change the plots significantly.

${ }^{16}$ We discussed this non monotonicity in Section 4.1 in relation to equation (24a).

${ }^{17}$ See Figures $c$ in Appendix E. This result is linked to the non monotonic behavior of $a_{M i j}$ with respect $\phi_{i j}$.
} 
and foreign affiliates in the integrated area. This result is driven by the relative more difficult conditions that country's $z$ firms are facing.

Result 2. The geographical exclusion of country $z$ encourages firms in $i$ and $j$ to increase their activity within as well as outside the integrated area. Further integration among PTA members, reduces the number of z-firms engaging in export and FDI in the integrated area.

Proof. See Appendix E.

Case B: Country $z$ is geographically integrated, i.e. $d_{i z}<d_{i j}=d_{j z}$

Case B considers the effect of a PTA when country- $z$ is excluded from the economic integration but enjoys a better geographically location. When trade and transportation barriers are sufficiently high, the FDI productivity cutoff for PTA-firms is unambiguously decreasing in $\phi_{i j} .{ }^{18}$ Thus all the results stay the same as in case A, but for the marginal cost of FDI. More precisely, due to larger transportation barriers between countries in the integrated area, deeper integration between $i$ and $j$ makes the FDI strategy relatively less expensive. Therefore, the number of $i$ and $j$ overseas affiliates unambiguously increases for any level of trade integration. Due to the location disadvantage between $i$ and $j$, the increase in $\phi_{i j}$ engenders a positive effect for both types of economic activities, exports and FDI. The compound effect of geographically accessibility and trade costs mitigates the role of intermediates which characterize the additional cost due to intra-firm trade. FDI and export activities in the integrated area become complement. In line with Chen (2009), the model finds that the integrated areas attract MNFs activity when characterized by access to a large size of markets.

Result 3. When countries belonging to a PTA are separated by important geographical barriers, deeper trade integration results in fostering both export and FDI activity within and outside that integrated region. FDI and exports become complementary activities for firms in the PTA area.

Proof. See Appendix F.

\subsubsection{Impact of changes in tariff frictions: circle}

To eliminate cross country differences in centrality, we consider a geographical space in which the three countries are evenly spaced around a circle so that shipping between any two locations takes place through the center, i.e. $d_{i j}=d_{i z}=d$. Abstracting from transport frictions, we again consider a PTA between countries $i$ and $j$ to explain how changes in bilateral trade frictions, affect countries' equilibrium distribution of activity. The absence of transport differences, changes the supply patterns in the integrating block.

Comparative statics on equilibrium cutoffs reveals that few firms in the PTA will choose the FDI mode of supply. The absence of transport differences between countries makes the cost

\footnotetext{
${ }^{18}$ This result is related to equation (24a). More specifically, $\eta \gamma_{i j}^{\eta-1} \phi^{\eta-1}$ is here larger than one: transportation barriers between $i$ and $j$ are sufficiently high that the FDI cutoff of firms in the integrated area, $a_{M i j}$, is increasing in $\phi_{i j}$.
} 
of FDI relatively higher than the cost of export. Thus eliminating cross country differences in centrality changes the way in which number of firms are affected: deeper trade integration advantages only export activities.

Deeper integration implies a decline in the number of overseas affiliates within the integrated area and an increase of exporting firms. Similarly to case A, further integration between $i$ and $j$ encourages exporters at the expenses of FDI activity. This fosters the substitutability result. Differently from both cases $\mathrm{A}$ and $\mathrm{B}$, the PTA reduces the number of $i$ - and $j$ exporters and overseas affiliate entering the excluded country. The absence of country differences in centrality, reinforces the home market effect: the overall number of foreign suppliers entering country $z$ is reduced.

Similarly to cases A and B, deeper trade integration reduces the number of $z$-firms entering the PTA area as exporters and foreign affiliates Notice also that the PTA signed between country $i$ and $j$ makes more firms to survive in the excluded country due to less competition. This result is driven by the concentration of economic activities in the integrated area, which reduces the competitive pressures in country $z$. This results in more inefficient firms surviving in country $z$; the number of active firms in country $z$ is increasing.

Result 4. When geographical space is symmetric, export and FDI activities between PTA members become perfect substitutes. The absence of different accessibility to foreign markets deepens the concentration of economic activities in the integrated area.

Proof. See Appendix G.

The less sensitive FDI activity is to trade barriers, the more likely is that FDI and export activities behave as substitute, i.e. confirming the proximity versus concentration hypothesis. In this scenario, a trade integration between countries $i$ and $j$ forces the least productive FDI firms to move out of the competitive integrated markets. In the integrated area, the substitutability between FDI and exports activities is re-established due to the smaller role played by transport barriers in the FDI variable costs with respect to export variable cost.

\subsection{Discussion}

Some of the above results are in line with Melitz (2003): trade liberalization, between $i$ and $j$, allows previously non-exporting firms to become exporters in their respective markets. However, the existence of intra-firm trade as well as different geographical structures, change the classical framework. Export and FDI can then be complement or substitute activities depending on the level of trade and transport costs. The discriminatory effect of PTA on the excluded country $z$ changes accordingly to the relationship existing between export and FDI. Complementarity results in reducing the concentration of economic activities into the integrated region. The opposite is true in case of substitution.

The discriminatory effect of a PTA in terms of concentration of economic activities seems to be more important when countries are more similar in terms of locations: in this case the integrated area becomes the core. Conversely, when countries strongly differ in terms of locations, the effect of redirecting economic activities outside the excluded country is reduced. When differences exist at too many level (transportation, level of heterogeneity within a country, etc.), the core outcome is less likely. 
Therefore the results suggest that the behavior of the three country model is different to that of the two-country model. The three country model allows us to give a role to economic geography and to consider special cases which deliver different patterns in terms of organization of firms' supply strategy. The main result is that the existence of geographical differences reduce the effect of discriminatory trade liberalization on the reorganization of modes supply strategy. Thus, on the one side, when geography is important, the integrated area experiences relatively less concentration of economic activities, such as trade and FDI. On the other side, these economic activities move out of the third country and concentrate exclusively within the PTA area when cross country differences in centrality are eliminated.

This set up allow us to say something in terms of export platform. In both sections 4.1 and 4.2 was found a reduction in the number of $z$-firms exporting or doing FDI. In case in which country $z$ is geographically excluded, as in case A, $z$-firms can be better off if using an export platform strategy: open a foreign affiliate in $i$ and from there export to country $j$ enjoying reduced trade costs. This to take advantage of the fact that export strategy is cheaper within the integrated region.

\section{$5 \quad$ Welfare Effects of Trade Liberalization}

Let's examine now the welfare effects in the perfectly symmetric scenario. To examine the welfare of consumers we focus on the indirect utility function. Since the indirect utility function is given by $V=\beta E / P$, where $\mathrm{P}$ is the standard CES price index, we can examine the welfare effects simply by examining how $\mathrm{P}$ changes. ${ }^{19}$ A greater openness will increase the welfare by lowering the price index, and by increasing average productivity. Instead, higher transport costs increase the price index, lowering welfare.

For the asymmetric case, we need to consider the indirect utility functions for the integrated area and for the excluded country $z$. Since deeper economic integration between $i$ and $j$ reduces competition in country $z$, the price index $P_{z}$ is increasing lowering welfare. The integrated area instead continues to experience welfare gains due to larger amount of foreign varieties.

\section{Conclusion}

In this paper, we consider the effects of different geographical spaces (e.g. transport costs) and border trade frictions (e.g., tariffs) on the location of firms. Starting with the symmetric liberalization episode, where geography plays no role, we then analyse asymmetric liberalization (PTA) and focus on two geographical spaces. First, we consider different accessibility to foreign markets in terms of transport barriers. Then, we analyse the case without cross-country differences in centrality (all countries lie at the same geographical distance)

Discriminatory trade liberalization modify the reorganization of modes supply strategy in the two geographical spaces considered. After integration, the new economic block experiences tougher competition. This results in shrinking the excluded country's economic activity, which does not enjoy larger economic integration. In country $z$ firms are forced to become more productive in both mode of supply strategies, export and FDI. Differently, the integrating

\footnotetext{
${ }^{19}$ Without loss of generality, in this welfare analysis we are only concerned about the differentiated good.
} 
block enjoys the entry of new exporting firms. The results for multinationals are more complex and depend on the geographical space considered.

The model makes three contributions to the existing literature. First, we enrich the spatial pattern of FDI, so that it depends on firm characteristics and intra-firm trade. This generates a more complex outcome than the standard proximity versus concentration model. Second, by introducing firm heterogeneity, we characterize the concentration of economic activities in each specific geographical space considered. Third, we shed light on the effects of discriminatory trade liberalization in different geographical structures. 


\section{References}

[1] Alfaro, L., Charlton, A., 2009. "Intra-Industry Foreign Direct Investment," American Economic Review, 99(5).

[2] Antras, P., Fritz Foley, C. "Regional Trade Integration and Multinational Firm Strategies," in Barro, R. and J-W. Lee (eds.), Costs and Benefits of Economic Integration in Asia, Oxford University Press, 2011.

[3] Baldwin, R.E., Forslid, R., Martin, Ph., Ottaviano, G.I.P., Robert-Nicoud, F., 2003. Economic Geography and Public Policy. Princeton Univ. Press, Princeton.

[4] Baldwin, R.E., 2005. "Heterogeneous Firms and Trade: Testable and Untestable Properties of the Melitz Model". NBER Working Paper No. 11471, National Bureau of Economic Research, Inc.

[5] Baltagi, B.H., Egger, P., Pfaffermayr, M., 2006. Estimating models of complex FDI: are there thirdcountry effects?. Journal of Econometrics, 140 (1), 260-281.

[6] Barba Navaretti, G. and A. Venables (2004), Multinational Firms in the World Economy (Princeton, NJ: Princeton University Press).

[7] Behrens, K., Lamorgese, A.R., Ottaviano, G.I.P., and Tabuchi, T., 2009. "Beyond the home market effect: Market size and specialization in a multi-country world," Journal of International Economics, Elsevier, vol. 79(2), pages 259-265.

[8] Behrens, K., Lamorgese, A.R., Ottaviano, G.I.P. and Tabuchi, T., 2007. "Changes in transport and non-transport costs: Local vs global impacts in a spatial network," Regional Science and Urban Economics, Elsevier, vol. 37(6), pages 625-648.

[9] Bernard, A., Jensen, J. B., Redding, S., Schott, P., 2010. "Intrafirm Trade and Product Contractibility," American Economic Review Papers \& Proceedings 100(2): 444-448.

[10] Bernard, A., Jensen, J. B., Redding, S., Schott, P., 2007. Firms in International Trade. Journal of Economic Perspective, 21 (3), 105-130.

[11] Blomstrom, M. and Kokko, A., 1997. "Regional Integration and Foreign Direct Investment," NBER Working Papers 6019, National Bureau of Economic Research, Inc.

[12] Blonigen, B.A., Davies, R.B., Naughton, H.T., Waddell, G.R., 2007. FDI in Space: Spatial Autoregressive Relationships in Foreign Direct Investment. European Economic Review, 51 (5), 1303-1325.

[13] Brainard, S.L., 1993. A Simple Theory of Multinational Corporations and Trade with a Trade-Off Between Proximity and Concentration. NBER Working Papers 4269, National Bureau of Economic Research, Inc.

[14] Brainard, S.L., 1997. "An Empirical Assessment of the Proximity-Concentration Trade-off between Multinational Sales and Trade," American Economic Review, 87 (4), 520-44. 
[15] Chen, M. X. and Moore, M.O., 2010. "Location decision of heterogeneous multinational firms," Journal of International Economics, Elsevier, vol. 80(2), pages 188-199, March.

[16] Chen, M.X., 2009. "Regional Economic Integration and Geographic Concentration of Multinational Firms" European Economic Review, 2009, vol. 53(3), pp. 355-375.

[17] Freund, C. and Ornelas, E., 2010. "Regional Trade Agreements," Annual Review of Economics 2, 139-166.

[18] Fujita, M., Krugman, P., Venables, A.J., 1999. The Spatial Economy. Cities, Regions and International Trade. MIT Press, Cambridge.

[19] Hanson, G.H., Mataloni, R.J., Slaughter, M.J., 2001. Expansion Strategies of U.S. Multinational Firms. NBER Working Papers 8433, National Bureau of Economic Research, Inc.

[20] Head, K.,Ries, J., 2004. "Exporting and FDI as Alternative Strategies," Oxford Review of Economic Policy, Oxford University Press, vol. 20(3), pages 409-423, Autumn.

[21] Helpman, E., Melitz, M.J., Yeaple, S.R., 2004. "Export versus FDI with Heterogeneous Firms," American Economic Review, 94 (1), 300-316.

[22] Horstmann, I.J., Markusen, J.R., 1992. "Endogenous market structures in international trade (natura facit saltum)," Journal of International Economics, 32 (1-2), 109-129.

[23] Krugman, P., 1980. "Scale Economies, Product Differentiation, and the Pattern of Trade," American Economic Review, 70 (5), 950-59.

[24] Limao, N., 2007. "Are Preferential Trade Agreements with Non-trade Objectives a Stumbling Block for Multilateral Liberalization, Review of Economic Studies, 74 (2007), 821855.

[25] Melitz, M. J., 2003. "The Impact of Trade on Intra-Industry Reallocations and Aggregate Industry Productivity," Econometrica, 71 (6), 1695-1725.

[26] Yeaple, S.R., W., Keller, 2012. "Gravity in the Knowledge Economy," forthcoming American Economic Review.

[27] WTO, 2011. World Trade Report 2011, The World Trade Organization, Geneva. 


\section{A Cost Minimization Problem}

In order to find the equilibrium operating profits, we solve the minimization problem of the firm:

$$
\min \quad y_{1} p_{1}+y_{2} \quad \text { s.t. } x(v)=\left[x(v)-\frac{1}{a}\left(\frac{y_{1}}{\eta}\right)^{\eta}\left(\frac{y_{2}}{1-\eta}\right)^{1-\eta}\right]
$$

Since labour is the only factor of production and the pricing condition implies $p_{h}=1=w$, total costs under each mode are described as follows:

$$
\begin{array}{r}
T C_{D}=x(v) a(v)+f_{D} \\
T C_{X i j}=x(v) a(v) d_{i j} \tau_{i j}+f_{X} \\
T C_{M i j}=x(v) a(v)\left(d_{i j} \tau_{i j}\right)^{\eta}+f_{M}
\end{array}
$$

\section{B Free Entry and Price Index for Symmetric Case}

\section{Free Entry}

It is possible to describe the equilibrium which characterizes this economy. In order to do so, we need to specify some other equilibrium equations, namely the free entry condition and the price index.

Free entry ensures equality between the expected operating profits of a potential entrant and the entry cost, $E(\pi)-f_{I}$. This condition holds for all type of firms. The cumulative density function is $G(a)$, with support: $\left[0, \ldots, a_{0}\right]$. The free entry condition can be defined as:

$$
\int_{0}^{a_{D}} \pi_{D} d G(a)+\sum_{j=1}^{N-1}\left(\int_{a_{M, i j}}^{a_{X, i j}} \pi_{X, i j} d G(a)+\int_{0}^{a_{M, i j}} \pi_{M, i j} d G(a)\right)=f_{I}
$$

Since we are in the symmetric case, the expressions below are reported without subscripts $i$ and $j$. Using the profit conditions (7)-(9), we obtain:

$$
\begin{gathered}
\int_{0}^{a_{D}}\left(\left(\frac{\sigma}{\sigma-1}\right)^{(1-\sigma)} \frac{\beta E a^{1-\sigma}}{P^{1-\sigma} \sigma}-f_{D}\right) d G(a)+(N-1) \int_{a_{M}}^{a_{X}}\left(\left(\frac{\sigma}{\sigma-1}\right)^{(1-\sigma)} \frac{\phi \gamma \beta E a^{1-\sigma}}{P^{1-\sigma} \sigma}-f_{X}\right) d G(a)+ \\
(N-1) \int_{0}^{a_{M}}\left(\left(\frac{\sigma}{\sigma-1}\right)^{(1-\sigma)} \frac{(\phi \gamma)^{\eta} \beta E a^{1-\sigma}}{P^{1-\sigma} \sigma}-f_{M}\right) d G(a)=f_{I}
\end{gathered}
$$

where $\phi=\tau^{1-\sigma}$ is freeness of trade, $\gamma=d^{1-\sigma}$ is the parameter that takes into consideration the locations; finally $P^{1-\sigma}$ is a weighted average of the marginal costs corrected for markups of all firms active in the market. Let's spend some more words on this term, $P^{1-\sigma}$.

In every country this weighted average, $P^{1-\sigma}$, is characterized by all the brands offered in that particular country. Brands offered by domestic firms, for which the consumer price is $a \sigma /(\sigma-1)$; brands offered by foreign exporters, for which the consumer price is $a \sigma d \tau /(\sigma-1)$; and finally, brands supplied by foreign subsidiaries, with consumer price $a \sigma(\tau d)^{\eta} /(\sigma-1)$. 
Therefore:

$$
\begin{gathered}
P^{1-\sigma}=\left(\frac{\sigma}{\sigma-1}\right)^{(1-\sigma)} n \int_{0}^{a_{D}} a^{1-\sigma} d G\left(a / a_{D}\right)+ \\
\left(\frac{\sigma}{\sigma-1}\right)^{(1-\sigma)} n(N-1)\left[\int_{0}^{a_{M}}[\phi \gamma]^{\eta} a^{1-\sigma} d G\left(a / a_{D}\right)+\int_{a_{M}}^{a_{X}} \phi \gamma a^{1-\sigma} d G\left(a / a_{D}\right)\right]
\end{gathered}
$$

where $n$ represents the measure of varieties available in the country.

\section{Parameterization: Pareto Distribution}

The fact that the free entry condition and the price index depend on the probability distribution implies that in order to have explicit solutions for this model, we need to assume a particular functional form for G(a). Following the empirical literature on firm size distribution (see Axtell 2001 and HMY), we use as an approximation the Pareto distribution. The cumulative distribution function of a Pareto random variable $a$ is:

$$
G(a)=\left(\frac{a}{a_{0}}\right)^{k}
$$

where $k$ and $a_{0}$ are the shape and scale parameter, respectively. Note that $\mathrm{k}=1$ implies a uniform distribution on $\left[0, a_{0}\right]$. The shape parameter $\mathrm{k}$ represents the dispersion of cost draws. An increase in $\mathrm{k}$ would imply a reduction in the dispersion of firm productivity-draws. Hence, the higher is $\mathrm{k}$ the smaller is the amount of heterogeneity. We can now use this Pareto distribution to derive the price index and the free entry condition.

As we said, firms offer a price only if they have at least a productivity of $1 / a_{D}$. Hence, the cumulative distribution is defined on a support $\left[0, \ldots, a_{D}\right]$. We can now solve the symmetric price index to obtain:

$$
P^{1-\sigma}=\left(\frac{\sigma}{\sigma-1}\right)^{(1-\sigma)} \frac{n}{1-\frac{1}{b}} a_{D}^{1-\sigma}\left[1+T^{1-b}(N-1)(\phi \gamma)^{b}+V^{1-b}(N-1)\left[(\phi \gamma)^{\eta}-\phi \gamma\right]^{b}\right]
$$

where $b=\frac{k}{\sigma-1} ; T=f_{X} / f_{D}$ and $V=\left(f_{M}-f_{X}\right) / f_{D}$. In order for the integral to converge we assume that $b>1$.

Rewriting now the free entry condition in (26) using the Pareto distribution we obtain:

$$
\begin{gathered}
\left(\frac{\sigma}{\sigma-1}\right)^{(1-\sigma)} \frac{\beta E}{\sigma P^{1-\sigma}}\left[\int_{0}^{a_{D}} a^{1-\sigma} d G(a)+(N-1) \int_{0}^{a_{M}}(\phi \gamma)^{\eta} a^{1-\sigma} d G(a)+(N-1) \int_{a_{M}}^{a_{X}} \phi \gamma a^{1-\sigma} d G(a)\right] \\
=f_{D} G\left(a_{D}\right)+(N-1)\left(f_{X} G\left(a_{X}\right)-f_{X} G\left(a_{M}\right)+f_{M} G\left(a_{M}\right)\right)+f_{I}
\end{gathered}
$$

We can now use (29), (30), and the ratio of the cut-off conditions to obtain the closed form solutions in Section 3. 


\section{Proof of Result 1}

In a perfectly symmetric set up, with only two countries, differentiating (17) with respect to $\phi$ gives:

$$
\frac{\partial a_{M}}{\partial \phi}=\frac{\partial}{\partial \phi} a_{0}\left[\frac{(b-1) f_{I}}{(1+\Psi+\Omega)}\left[(\phi \gamma)^{\eta}-(\phi \gamma)\right]^{b} \frac{V^{1-b}}{f_{M}-f_{X}}\right]^{\frac{1}{k}}
$$

The terms that depend on $\phi$ are $\Psi, \Omega$ and the small square bracket. Equation (31) can be simplified to

$$
\frac{\partial}{\partial \phi} \frac{\left[(\phi \gamma)^{\eta}-(\phi \gamma)\right]^{b}}{(1+\Psi+\Omega)}
$$

which yields

$$
=\frac{(1+\Psi+\Omega) b\left[(\phi \gamma)^{\eta}-(\phi \gamma)\right]^{b-1}\left(\eta \phi^{\eta-1} \gamma^{\eta}-\gamma\right)-(\partial \Psi / \partial \phi+\partial \Omega / \partial \phi)\left[(\phi \gamma)^{\eta}-(\phi \gamma)\right]^{b}}{(1+\Psi+\Omega)^{2}}
$$

Since the magnitude of the first term in the numerator is always bigger than the second term, the sign of (31) is determined by the sign of

$$
\left(\eta \phi^{\eta-1} \gamma^{\eta}-\gamma\right)
$$

Therefore, substitutability between export and FDI exists if the following condition holds:

$$
\frac{\partial a_{M}}{\partial \phi}<0 \Longleftrightarrow \frac{\partial}{\partial \phi} \frac{\left[(\phi \gamma)^{\eta}-(\phi \gamma)\right]^{b}}{(1+\Psi+\Omega)}<0 \Longleftrightarrow \eta(\phi \gamma)^{\eta-1}<1
$$

The last condition in (34) is true for sufficiently low frictions, $\tau$ and $d$, and sufficiently low $\eta$. Thus, low trade and transport frictions ensure substitutability between export and FDI.

\section{Free Entry and Price Index for Asymmetric Case}

Section 4 investigate the effects of PTA with different spatial networks. Considering countries $i$ and $j$ as perfectly symmetric and different from country $z$, we analyze the effect of a PTA between $i$ and $j$. The price index is thus identical in countries $i$ and $j$. The same for their free entry conditions and cutoffs. To solve the model, we rewrite the free entry for country $i(=j)$ using the cutoffs and the Pareto distribution, such as: ${ }^{20}$

$$
\begin{gathered}
\frac{1}{b-1}\left[f_{D}^{1-b} B_{i}^{b}+\left(f_{M}-f_{X}\right)^{1-b}\left[\left(B_{j=i}\left(\left(\phi_{i j} \gamma_{i j}\right)^{\eta}-\phi_{i j} \gamma_{i j}\right)\right)^{b}+\left(B_{z}\left(\left(\phi_{i z} \gamma_{i z}\right)^{\eta}-\phi_{i z} \gamma_{i z}\right)\right)^{b}\right]\right. \\
\left.+f_{X}^{1-b}\left[\left(\phi_{i j} B_{j=i}\right)^{b}+\left(\phi_{i z} B_{z}\right)^{b}\right]\right]=f_{I}
\end{gathered}
$$

Similarly, the free entry in country $z$ can be obtained:

$\frac{1}{b-1}\left[f_{D}^{1-b} B_{z}^{b}+2\left(f_{M}-f_{X}\right)^{1-b}\left(B_{i=j}\left(\left(\phi_{z i} \gamma_{z i}\right)^{\eta}-\phi_{z i} \gamma_{z i}\right)\right)^{b}+2 f_{X}^{1-b}\left(\phi_{z i} B_{i=j}\right)^{b}\right]=f_{I}$

This system of two equations, (35) and (36), can be solved for $B_{i}$ and $B_{z}$ to obtain closed

\footnotetext{
${ }^{20}$ Symmetry between country $i$ and $j$ implies that $B_{i}=B_{j}$.
} 
form solutions for the eight cutoffs. Even though analytical solutions for $B_{i}$ and $B_{z}$ can be computed, comparative statics with respect to $\phi_{i j}$ is difficult to interpret. For this reason we rely on numerical solutions. Solving numerically the B's allow us to characterize their evolution with respect to deeper integration between countries $i$ and $j$. We get,

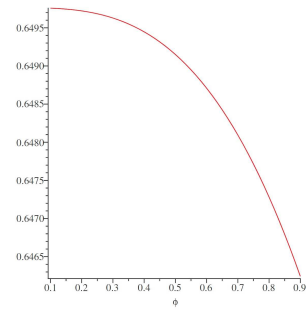

(a) $B_{i}$

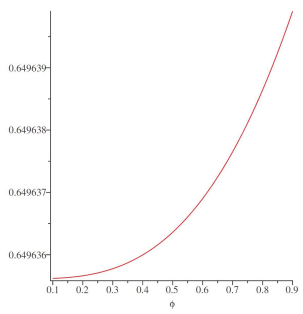

(b) $B_{z}$

where the parameters values are: $\sigma=3, f_{I}=0.061, k=3, \beta=0.4, \eta=0.4$. Values for the fixed costs are chosen so to satisfy the ranking condition. Notice that these graphical results hold for every spatial network considered (triangle or circle).

\section{E Proof of Result 2 (Case A)}

In what follows, we provide graphical results to establish the impact of a preferential trade agreement between countries $i$ and $j$ when country- $z$ is not only excluded from the economic integration but also geographically disadvantaged. The following comparative statics assume parameter values such that: $d_{i j}=2, d_{i z}=d_{j z}=5, \phi_{i z}=\phi_{j z}=0.3, \sigma=3, f_{I}=0.061, k=3$, $\beta=0.4, \eta=0.4$.

The equilibrium number of exporting firms used for the comparative statics is:

$$
n_{X i j}=n_{D i} \int_{a_{M i j}}^{a_{X i j}} d G\left(a / a_{D i}\right)
$$

The equilibrium number of foreign affiliates is given by:

$$
n_{M i j}=n_{D i} \int_{0}^{a_{M i j}} d G\left(a / a_{D i}\right)
$$

Using equations (37) and (38), we show the graphical implications on the number of firms of the non monotonic FDI cutoffs within the integrated area:

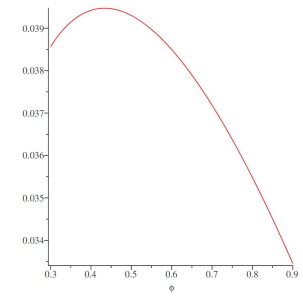

(c) $n_{M i j}$

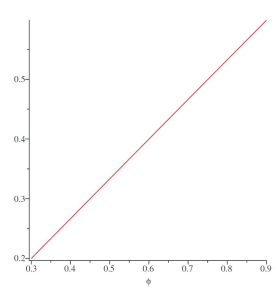

(d) $n_{X i j}$ 
The geographical exclusion of country $z$ boosts economic activities of PTA-firms within and outside the integrated area,

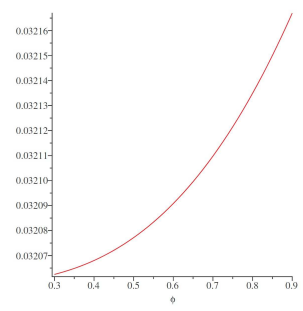

(e) $n_{M i z}$

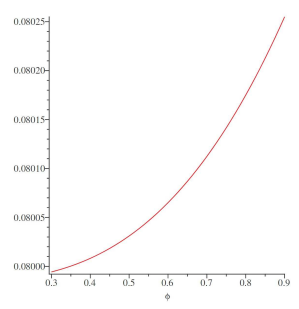

(f) $n_{X i z}$

The number of exporting and affiliate activities that enters in country $z$ from $i$ and $j$ is increasing. The reduced concentration of economic activities in the integrated area is captured by the fact that both $n_{X i z}$ and $n_{M i z}$ are increasing as well as $n_{M i j}$ and $n_{X i j}$.

The opposite is true for firms in country $z$ : Both $n_{X z i}$ and $n_{M z i}$ are decreasing.

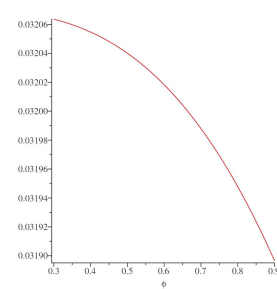

(g) $n_{M z i}$

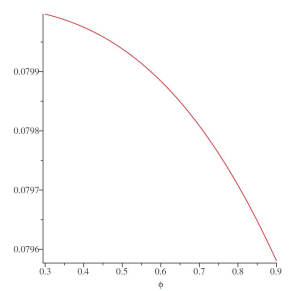

(h) $n_{X z i}$

\section{F Proof of Result 3 (Case B)}

In what follows, we provide graphical results to establish the impact of a preferential trade agreement between countries $i$ and $j$ when country- $z$ enjoys a better geographical location. The following comparative statics assume parameter values such that: $d_{i j}=d_{j z}=10, d_{i z}=2$, $\phi_{i z}=\phi_{j z}=0.3, \sigma=3, f_{I}=0.061, k=3, \beta=0.4, \eta=0.4$.

Case $\mathrm{B}$ differs with respect to Case A because now there is no ambiguity concerning the reaction of $a_{M i j}$ : export and FDI are complementary activities in the integrated area. Thus, comparative statics for equations (37) and (38) in this geographical space gives:

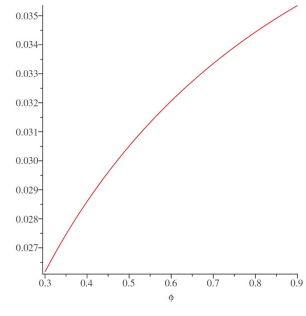

(i) $n_{M i j}$

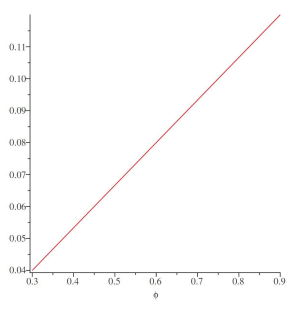

(j) $n_{X i j}$

Economic activities of PTA-firms are boosted inside and outside the integrated area. Thus, a similar plot to the one above describes the number of firms entering in the excluded country: the number of exporting and affiliates activities that enters country $z$ is increasing. The existence of geographical differences reduces the effect of discriminatory trade policy. Economic activities of $i$ and $j$ firms are increasing within and outside the PTA $\left(n_{X i j}\right.$ and $n_{M i j}$ as well as 
$n_{X i z}$ and $n_{M i z}$ are increasing). Differently from case $\mathrm{A}$, here this result is independent on the level of integration, $\phi_{i j}$. Similarly to case A, the number of exporting and affiliates activities from country $z$ are both decreasing $\left(n_{X z i}\right.$ and $n_{M z i}$ are decreasing).

\section{G Proof of Result 4}

In what follows, we abstract from transport frictions to explore graphically the impact of a preferential trade agreement between countries $i$ and $j$. The following comparative statics assume parameter values such that: $d_{i j}=d_{j z}=d_{i z}=1, \phi_{i z}=\phi_{j z}=0.3, \sigma=3, f_{I}=0.061$, $k=3, \beta=0.4, \eta=0.4$.

Using equations (37) and (38), we can show the graphical results for the behavior of the number of firms linked to the existence of neat substitutability between export and FDI in the integrated area:

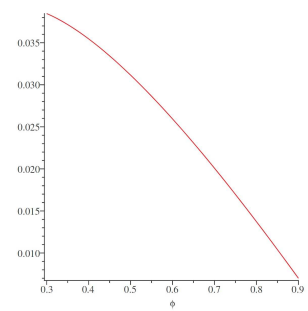

(k) $n_{M i j}$

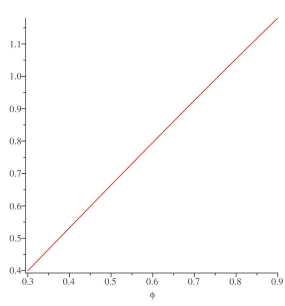

(1) $n_{X i j}$

Only export activities of PTA-firms is boosted in the integrated area. Differently, the number of exporting and affiliates activities that enters in country $z$ from $i$ and $j$ is decreasing:

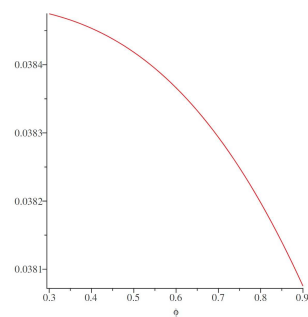

(m) $n_{M i z}$

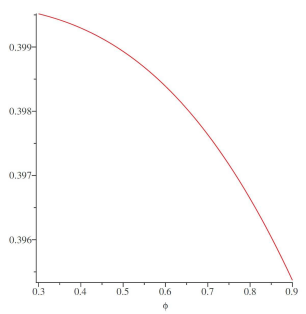

(n) $n_{X i z}$

The absence of different accessibility to foreign markets, deepens the concentration of export activities in the integrated area. This result is captured by the fact that while $n_{X i z}$ and $n_{M i z}$ are decreasing, $n_{X i j}$ is increasing. The smaller role played by distance, generates substitution between export and FDI in the PTA region, thus $n_{M i j}$ is decreasing. Similarly to the previous cases, the number of exporting and affiliates activities from country $z$ are both decreasing.

The result is different from cases A and B: relocation here occurs exclusively within the integrated area. 